\title{
Study on the Intelligent Evaluation System of Tunnel Frost Damage in Cold Regions Based on the Fuzzy Comprehensive Evaluation Model
}

\author{
Dao-yuan Wang $\left(\mathbb{D},{ }^{1,2}\right.$ Yong-quan Zhu, ${ }^{2}$ Guang-yao Cui $\left(\mathbb{D},{ }^{3}\right.$ Yong-jun Luan, ${ }^{4}$ Hai-long Cui, ${ }^{4}$ \\ Liang Sun, ${ }^{5}$ Yong-jie Sun, ${ }^{4}$ Yue Wang, ${ }^{4}$ and Jin-xiu Yuan $\left({ }^{1}{ }^{1}\right.$ \\ ${ }^{1}$ Department of Civil Engineering, Hebei Jiaotong Vocational and Technical College, Shijiazhuang, Hebei 050091, China \\ ${ }^{2}$ School of Civil Engineering, Shijiazhuang Tiedao University, Shijiazhuang, Hebei 050043, China \\ ${ }^{3}$ School of Civil Engineering, North China University of Technology, Beijing 100144, China \\ ${ }^{4}$ Hebei Construction Group Corporation Limited, Baoding, Hebei 071052, China \\ ${ }^{5}$ Hebei Provincial Communications Planning and Design Institute, Shijiazhuang, Hebei 050000, China
}

Correspondence should be addressed to Dao-yuan Wang; wtg-888@163.com

Received 12 June 2020; Accepted 21 July 2020; Published 21 August 2020

Guest Editor: Yu-Sheng Shen

Copyright (c) 2020 Dao-yuan Wang et al. This is an open access article distributed under the Creative Commons Attribution License, which permits unrestricted use, distribution, and reproduction in any medium, provided the original work is properly cited.

\begin{abstract}
At present, the tunnel design specifications in China do not provide a clear and systematic intelligent evaluation system of tunnel frost damage in cold regions. Based on the research results of 122 seasonal frozen soil tunnels in high-latitude areas of China, four key influencing factors of geohydrology, temperature, surrounding rock, and engineering measures were determined, the intelligent fuzzy comprehensive evaluation model was established, the weights of all factors were considered, and the intelligent evaluation technology system of tunnel frost damage in cold areas had been put forward. Meanwhile, the rationality of the intelligent model was verified by a specific engineering case. The research suggests that the intelligent evaluation model of tunnel frost damage proposed in this paper can accurately describe the relationship of influencing factors of tunnel frost damage in cold areas, the weight of each influencing factor is calculated by using analytic hierarchy process, and the main risk sources of tunnel frost damage in cold areas are found out. The intelligent evaluation model is an efficient and practical method for Intelligent prediction of frost damage. By using the subordinate function method, the improvement from qualitative analysis to quantitative index calculation is realized. The blindness of engineering analogy construction is avoided, and the scientificity and accuracy of renovation measures for frost damage have been improved. At the same time, the research results provide a theoretical basis for the improvement of the intelligent evaluation system of tunnel frost damage in cold regions.
\end{abstract}

\section{Introduction}

With the implementation of the Belt and Road Initiative and the promotion of basic construction of the Beijing Winter Olympic Games, more and more tunnels are built in cold regions of seasonal frozen soil. The problems of frost damage of tunnels have been gradually highlighted, such as leakage of lining, ice hanging, water pouring from tunnel bottom, frost heaving of icing, cracking, crumbling and peeling of lining, freezing of the drainage system, thermal melting, and sliding of the tunnel portal.
In view of the problems of tunnel frost damage in cold areas, the tunnellers have carried out the research work on the temporal and spatial variation law of temperature field [1-9], thermal insulation, and prevention measures of frost damage [10-16]. However, the research on the intelligent evaluation system of tunnel frost damage in cold regions is rarely reported, mainly including as follows: according to the average temperature and freezing depth of the coldest month, the Qinghai-Tibet Plateau, Inner Mongolia, and Northeast China are divided into three cold regions, and the characteristics of frost damage are analyzed according to different cold regions 
[17]. The causes of tunnel frost damage in cold areas can be divided into three categories: external force, material cracking, and other reasons. The characteristics of tunnel frost damage in the cold area are qualitatively explained [18]. The frost damage of tunnels in cold areas is considered to be caused by vertical load, plastic load, and creep of the inclined slope, and corresponding preventive measures are put forward according to different classifications [19]. Based on the event tree theory, the frost damage level of tunnels in the cold region has been established, and the scientific and effective measures to control frost damage of tunnels in the cold region have been improved [20]. According to the fatigue strength of concrete frost damage, the durability of the concrete structure under freeze-thaw environment, and the action level of lining frost heaving force, the frost damage level of the tunnel in cold areas is divided, and corresponding preventive measures are put forward according to different classifications [21].

Based on the investigation results of 122 tunnels in highlatitude areas of China, four key influencing factors (geological hydrology, temperature, surrounding rock, and engineering measures) are determined, an intelligent fuzzy comprehensive evaluation model is established, and an intelligent evaluation system of tunnel frost damage in cold areas is proposed considering the weight relationship of key factors.

\section{Investigation of Tunnel Frost Damage in Cold Areas}

The data of 122 tunnels in cold regions in Northeast China and Inner Mongolia were collected. The frost damage of 12 tunnels is caused by unreasonable design, which accounts for $23 \%$ of the total number of tunnels. The frost damage of 27 tunnels is caused by the wrong construction method, which accounts for $53 \%$ of the total number of tunnels. The frost damage of 9 tunnels is due to improper operation and maintenance, which accounts for $18 \%$ of the total number of tunnels. The frost damage of 3 tunnels is caused by unreasonable remedial measures, which accounts for $6 \%$ of the total number of tunnels. The percentage of each influencing factor of tunnel frost damage is shown in Figure 1.

\section{Establishment of the Intelligent Evaluation System of Tunnel Frost Damage in Cold Regions}

3.1. Establishment of the Intelligent Evaluation Model. Considering the four basic influencing factors of temperature condition, hydrological condition, surrounding rock condition, and engineering measures, an intelligent evaluation model is established by the fuzzy comprehensive evaluation method, and the intelligent evaluation model of tunnel frost damage in cold regions is shown in Figure 2.

3.2. Establishment of Comment Collection. According to the degree of frost damage, the comments on the intelligent evaluation system of tunnel frost damage in cold areas are as follows:

$$
V=\left\{V_{1}, V_{2}, V_{3}, V_{4}\right\}=\{\mathrm{I}, \mathrm{II}, \mathrm{III}, \mathrm{IV}\} .
$$

In this formula, class I is no frost damage or slight frost damage, class II is moderate frost damage, class III is relatively serious frost damage, and class IV is serious frost damage.

The classification of tunnel frost damage in cold regions is shown in Table 1.

3.3. Determination of the Membership Function. The intelligent evaluation system of tunnel frost damage in cold areas includes 10 quantitative indexes (air temperature outside the tunnel, ground temperature of the surrounding rock, driving density, wind speed inside the tunnel, void area length between surrounding rock and lining, annual precipitation, blockage rate of the drainage pipe, buried depth of the tunnel, fracture rate of the surrounding rock, and lining strength) and 6 qualitative indexes (waterproof design of three joints, solubility of the surrounding rock, design problems, construction problems, operation and maintenance problems, and remedial measures). Among them, the quantitative indexes can be divided into 7 positive quantitative indexes (air temperature outside the tunnel, traffic density, wind speed inside the tunnel, void area length between surrounding rock and lining, annual precipitation, blockage rate of the drainage pipe, and fracture rate of the surrounding rock) and 3 negative quantitative indexes (ground temperature of the surrounding rock, buried depth of the tunnel and lining strength).

3.3.1. Determine the Membership Function of the Quantitative Index. The reduced half trapezoid distribution function is selected as the membership function of the positive-type quantitative index. The membership function is shown in formulae $(2) \sim(5)$. The parameters of the membership function of the positive-type quantitative index are shown in Table 2.

$$
\begin{aligned}
& \mu_{1}= \begin{cases}1, & x<S_{1}, \\
\frac{S_{2}-x}{S_{2}-S_{1}} & S_{1} \leq x \leq S_{2}, \\
0, & x>S_{2},\end{cases} \\
& \mu_{2}= \begin{cases}\frac{0,}{\frac{x-S_{1}}{S_{2}-S_{1}},} & S_{1}<x \leq S_{1}, x>S_{3}, \\
\frac{S_{3}-x}{S_{3}-S_{2}}, & S_{2}<x \leq S_{3},\end{cases}
\end{aligned}
$$




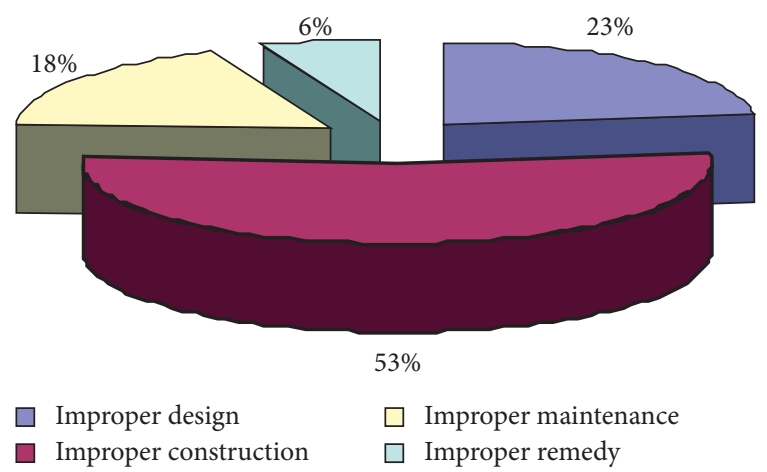

FIGURE 1: Proportion of influencing factors of tunnel frost damage.

$$
\begin{aligned}
& \mu_{3}= \begin{cases}0, & x \leq S_{2}, x>S_{4}, \\
\frac{x-S_{2}}{S_{3}-S_{2}}, & S_{2}<x \leq S_{3}, \\
\frac{S_{4}-x}{S_{4}-S_{3}}, & S_{3}<x \leq S_{4},\end{cases} \\
& \mu_{4}= \begin{cases}0, & x \leq S_{3}, \\
\frac{x-S_{3}}{S_{4}-S_{3}}, & S_{3}<x \leq S_{4}, \\
1, & x>S_{4},\end{cases}
\end{aligned}
$$

where $S_{1}, S_{2}, S_{3}$, and $S_{4}$ are determined by each critical state index in the evaluation benchmark.

The reduced half trapezoid distribution function is also selected as the membership function of the negative-type quantitative index. The membership function is shown in formulae $(6) \sim(9)$. The parameters of the membership function of the negative quantitative index are shown in Table 3.

$$
\begin{gathered}
\mu_{1}= \begin{cases}1, & x>S_{1}, \\
\frac{S_{2}-x}{S_{2}-S_{1}}, & S_{1} \geq x \geq S_{2}, \\
0, & x<S_{2},\end{cases} \\
\mu_{2}= \begin{cases}\frac{x-S_{1}}{S_{2}-S_{1},} & S_{1}>x \geq S_{2}, \\
\frac{S_{3}-x}{S_{3}-S_{2},} & S_{2}>x \geq S_{3},\end{cases} \\
\mu_{3}=\mu_{2}= \begin{cases}0, & x \geq S_{2}, x<S_{4}, \\
\frac{x-S_{2}}{S_{3}-S_{2}}, & S_{2}>x \geq S_{3}, \\
\frac{S_{4}-x}{S_{4}-S_{3}}, & S_{3}>x \geq S_{4},\end{cases}
\end{gathered}
$$

$$
\mu_{4}= \begin{cases}0, & x \geq S_{3}, \\ \frac{x-S_{3}}{S_{4}-S_{3}}, & S_{3}>x \geq S_{4}, \\ 1, & x<S_{4} .\end{cases}
$$

3.3.2. Determine the Membership Function of the Qualitative Index. Trapezoidal distribution function is selected as the membership function of the qualitative index, and its membership function is shown in formulae $(10) \sim(13)$ :

$$
\begin{aligned}
& \mu_{1}= \begin{cases}0, & x<0.75, \\
10 x-7.5 & 0.75 \leq x<0.85, \\
1, & x \geq 0.85,\end{cases} \\
& \mu_{2}= \begin{cases}0, & x<0.55, \\
10 x-05.5 & 0.55 \leq x<0.65, \\
1, & 0.65 \leq x<0.75, \\
8.5-10 x & 0.75 \leq x<0.85, \\
0, & x \geq 0.85\end{cases} \\
& \mu_{3}= \begin{cases}0, & x<0.35 \\
10 x-3.5 & 0.35 \leq x<0.65, \\
1, & 0.45 \leq x<0.55, \\
6.5-10 x & 0.55 \leq x<0.65, \\
0, & x \geq 0.65,\end{cases} \\
& \mu_{4}= \begin{cases}1, & x<0.35, \\
4.5-10 x & 0.35 \leq x<0.45, \\
0, & x \geq 0.45 .\end{cases}
\end{aligned}
$$

3.4. Determination of the Weighted Set. Analytic hierarchy process is used to determine the weighted set of the intelligent evaluation system of tunnel frost damage in cold regions. The steps are as follows: establish the evaluation model (Figure 2), build two judgment matrices, and calculate the relative weight of each index and consistency test.

The sensitivity of each index of temperature conditions is ground temperature of the surrounding rock, driving density, wind speed inside the tunnel, and air temperature outside the tunnel. The judgment matrix of temperature conditions is shown in Table 4.

The calculation results of the relative weight of four indexes under temperature conditions are as follows: $W_{U_{1}}=\left(W_{U_{11}}, W_{U_{12}}, W_{U_{13}}, W_{U_{14}}\right)=(0.10,0.40,0.30,0.20)$, $\lambda_{\max }=4, C I=0, C R=0<0.1$, and the conformance test meets the requirements.

The sensitivity of each index of the hydrological condition is void area length of the surrounding rock between lining, blockage rate of the drainage pipe, 


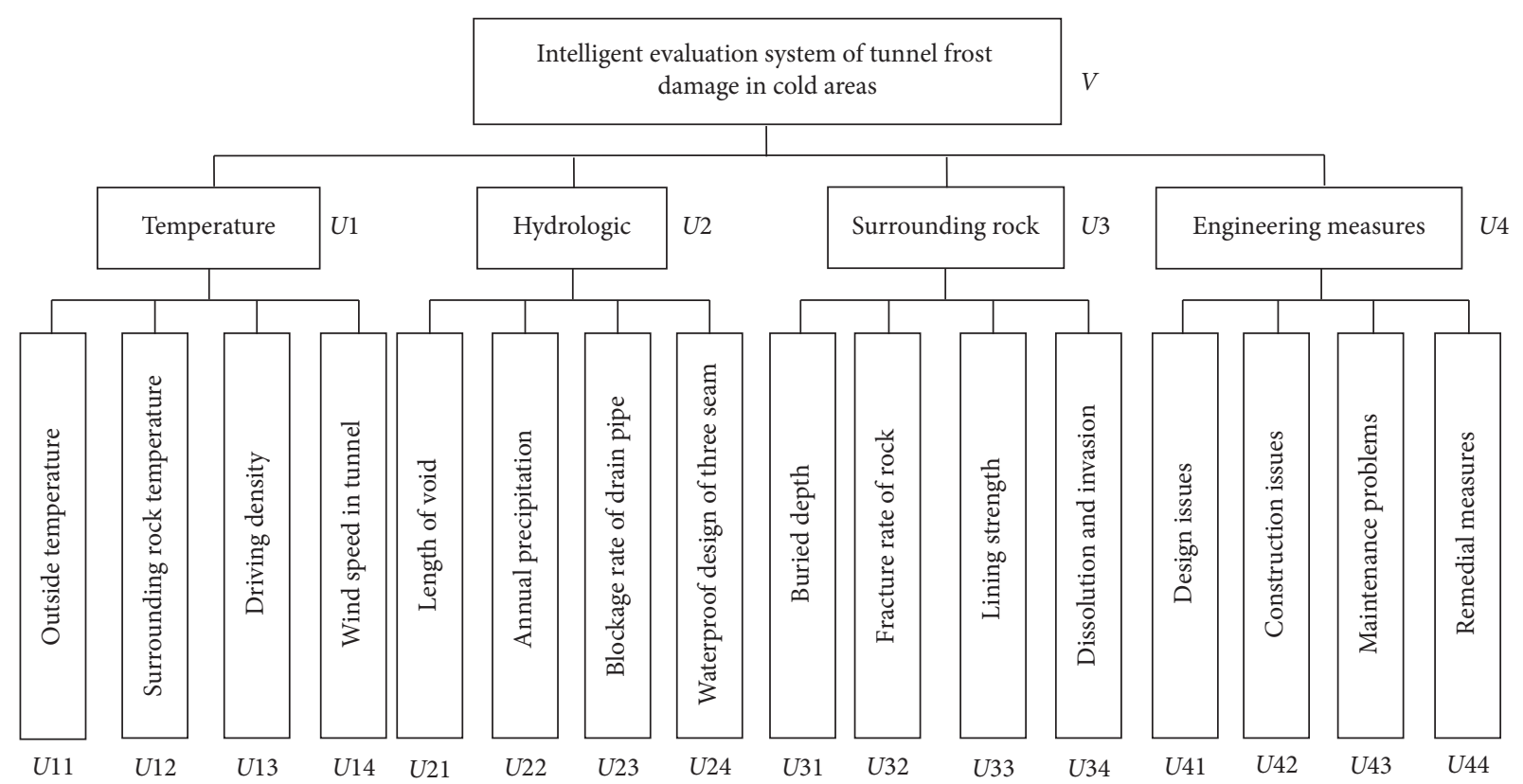

FIgURE 2: Frost damage intelligent evaluation model of the tunnel in cold areas.

TABLE 1: Classification of tunnel frost damage in cold regions.

\begin{tabular}{|c|c|c|}
\hline $\begin{array}{l}\text { Frost damage } \\
\text { classification }\end{array}$ & Judgment basis & $\begin{array}{l}\text { Average temperature in the } \\
\text { coldest month } /{ }^{\circ} \mathrm{C}\end{array}$ \\
\hline I & $\begin{array}{l}\text { Icing at the portal section, leakage and icing of the partial lining surface, slight } \\
\text { frost damage, no impact on traffic }\end{array}$ & $-5 \sim-10$ \\
\hline II & $\begin{array}{c}\text { Moderate serious icing at the portal section, moderate severe leakage and } \\
\text { freezing damage of the lining surface, affecting traffic }\end{array}$ & $-10 \sim-15$ \\
\hline III & $\begin{array}{l}\text { Relatively serious icing at the portal section, relatively severe leakage and } \\
\text { freezing damage of the lining surface, serious impact on traffic }\end{array}$ & $-15 \sim-25$ \\
\hline IV & $\begin{array}{l}\text { Serious crack of the lining surface, serious ice hanging in the tunnel, ice plug of } \\
\text { the drain system, traffic disruption }\end{array}$ & $<-25$ \\
\hline
\end{tabular}

TABle 2: Membership function parameters of the positive quantitative index.

\begin{tabular}{|c|c|c|c|c|}
\hline Positive quantitative index & $\mathrm{I}$ & II & III & IV \\
\hline Air temperature outside the tunnel $/{ }^{\circ} \mathrm{C}$ & -5 & -10 & -15 & -25 \\
\hline Driving density/(对/h) & 2 & 4 & 6 & 8 \\
\hline Wind speed inside the tunnel $/(\mathrm{m} / \mathrm{s})$ & 1 & 2 & 3 & 5 \\
\hline Void area length between surrounding rock and lining/m & 3 & 5 & 10 & 20 \\
\hline Annual precipitation $/ \mathrm{mm}$ & 200 & 600 & 1600 & 2500 \\
\hline Blockage rate of the drainage pipe & 0.2 & 0.5 & 0.8 & 0.9 \\
\hline Fracture rate of the surrounding rock & 0.001 & 0.5 & 10 & 15 \\
\hline
\end{tabular}

waterproof design of three joints, and annual precipitation. The judgment matrix of hydrological conditions is shown in Table 5 .

The calculation results of the relative weight of four indexes under hydrological conditions are as follows: $W_{U_{2}}=\left(W_{U_{21}}, W_{U_{22}}, W_{U_{23}}, W_{U_{24}}\right)=(0.49,0.10,0.25,0.16)$, $\lambda_{\text {max }}=4, C I=0, C R=0<0.1$, and the conformance test meets the requirements.

The sensitivity of each index of the surrounding rock condition is fracture rate of the surrounding rock, dissolution and invasion of the surrounding rock, lining strength, and tunnel buried depth. The judgment matrix of surrounding rock conditions is shown in Table 6 .

The calculation results of the relative weight of the four indexes under surrounding rock conditions are as follows: $W_{U_{3}}=\left(W_{U_{31}}, W_{U_{32}}, W_{U_{33}}, W_{U_{34}}\right)=(0.08,0.38,0.23,0.31)$, $\lambda_{\text {max }}=4, C I=0, C R=0<0.1$, and the conformance test meets the requirements.

According to the investigation on frost damage of 122 tunnels in seasonally cold regions in China (Figure 1), the sensitivity of each index of engineering measures is the design problem, the construction problem, the operation 
TABle 3: Membership function parameters of the negative quantitative index.

\begin{tabular}{lcccc}
\hline Negative quantitative index & I & II & III & IV \\
\hline $\begin{array}{l}\text { Ground temperature of the surrounding } \\
\text { rock } /{ }^{\circ} \mathrm{C}\end{array}$ & 25 & 15 & 10 & 5 \\
Buried depth of the tunnel/m & 600 & 500 & 300 & 100 \\
Lining strength & 0.66 & 0.5 & 0.33 & 0 \\
\hline
\end{tabular}

TABLE 4: Judgment matrix of temperature conditions.

\begin{tabular}{lcccc}
\hline$U_{1}$ & $U_{11}$ & $U_{12}$ & $U_{13}$ & $U_{14}$ \\
\hline$U_{11}$ & 1.000 & 0.250 & 0.333 & 0.500 \\
$U_{12}$ & 4.000 & 1.000 & 1.333 & 2.000 \\
$U_{13}$ & 3.000 & 0.750 & 1.000 & 1.500 \\
$U_{14}$ & 2.000 & 0.500 & 0.667 & 1.000 \\
\hline
\end{tabular}

TABLE 5: Judgment matrix of hydrological conditions.

\begin{tabular}{lcccc}
\hline$U_{2}$ & $U_{21}$ & $U_{22}$ & $U_{23}$ & $U_{24}$ \\
\hline$U_{21}$ & 1.000 & 5.000 & 2.000 & 3.000 \\
$U_{22}$ & 0.200 & 1.000 & 0.400 & 0.600 \\
$U_{23}$ & 0.500 & 2.500 & 1.000 & 1.500 \\
$U_{24}$ & 0.333 & 1.667 & 0.667 & 1.000 \\
\hline
\end{tabular}

TABLE 6: Judgment matrix of surrounding rock conditions.

\begin{tabular}{lcccc}
\hline$U_{3}$ & $U_{31}$ & $U_{32}$ & $U_{33}$ & $U_{34}$ \\
\hline$U_{31}$ & 1.000 & 0.200 & 0.333 & 0.25 \\
$U_{32}$ & 5.000 & 1.000 & 1.667 & 1.250 \\
$U_{33}$ & 3.000 & 0.600 & 1.000 & 0.750 \\
$U_{34}$ & 4.000 & 0.800 & 1.333 & 1.000 \\
\hline
\end{tabular}

and maintenance problem, and the unreasonable remedial measures. Among the four factors, temperature and hydrological conditions are the most important followed by engineering measures and surrounding rock conditions. The calculation results of the relative weight of four indexes under engineering measure conditions are as follows: $W_{U_{4}}=\left(W_{U_{41}}, W_{U_{42}}, W_{U_{43}}, W_{U_{44}}\right)=(0.23,0.53,0.18,0.06)$.

The judgment matrix of engineering measures is shown in Table 7 .

The calculation results of the relative weights of four basic influencing factors in the criteria layer are as follows: $W_{U_{V}}=\left(W_{U_{1}}, W_{U_{U}}, W_{U_{3}}, W_{U_{4}}\right)=(0.29,0.29,0.13,0.29)$, $\lambda_{\max }=4, C I=0, C R=0<0.1$, and the conformance test meets the requirements. The weight relationship between criterion level and index level is shown in Table 8.

3.5. Calculation Method of the Intelligent Fuzzy Comprehensive Evaluation Model. The weighted average evaluation model is used in the first-level and the second-level
TABLE 7: Judgment matrix of engineering measure conditions.

\begin{tabular}{lcccc}
\hline$U_{4}$ & $U_{41}$ & $U_{42}$ & $U_{43}$ & $U_{44}$ \\
\hline$U_{41}$ & 1.000 & 1.000 & 2.000 & 1.000 \\
$U_{42}$ & 1.000 & 1.000 & 2.000 & 1.000 \\
$U_{43}$ & 0.500 & 0.500 & 1.000 & 0.500 \\
$U_{44}$ & 1.000 & 1.000 & 2.000 & 1.000 \\
\hline
\end{tabular}

intelligent fuzzy comprehensive evaluation model, namely, model of $M(\circ, \oplus)$.

The calculation method of the first-level fuzzy comprehensive evaluation result is shown in the following formula:

$$
B_{k}=A_{k} \circ R_{k}=\left(B k_{1}, B k_{2}, B k_{3}, B k_{4}\right), \quad k=(1,2,3,4),
$$

where $A_{k}$ is the weight of the index layer and $R_{k}$ is the firstlevel fuzzy relation matrix.

The calculation method of the second-level fuzzy comprehensive evaluation result is shown in the following formula:

$$
B=A \circ B_{k}=\left(b_{1}, b_{2}, b_{3}, b_{4}\right) \quad(k=1,2,3,4),
$$

where $A$ is the weight of the criterion layer and $B_{k}$ is the firstlevel comprehensive evaluation result.

\section{Rationality Verification of the Intelligent Model}

4.1. Example Overview. The total length of the tunnel in cold regions is $2950 \mathrm{~m}$, the annual average precipitation in the tunnel site is $392.8 \mathrm{~mm}$, the annual average temperature is $6.2^{\circ} \mathrm{C}$, the extreme maximum temperature is $37.9^{\circ} \mathrm{C}$, the extreme minimum temperature is $-27.9^{\circ} \mathrm{C}$, the maximum freezing depth of soil is $192 \mathrm{~cm}$, the annual average wind speed is $1.8 \mathrm{~m} / \mathrm{s}$, and the maximum snow thickness is $18 \mathrm{~cm}$. Underground water is relatively rich, mainly bedrock fissure water.

4.2. Matrix of Fuzzy Relation. According to the geological data and monitoring data on-site, the value of influencing factors of frost damage in the tunnel portal section is shown in Table 9.

4.3. Operation of the First-Level Intelligent Fuzzy Comprehensive Evaluation Model. Firstly, the influencing factors of frost damage in the tunnel portal are substituted into the membership function, and the fuzzy relation matrix $R$ is obtained. Then, the first-level fuzzy comprehensive evaluation result is obtained by using the weighted average evaluation model: 
TAвLE 8: Weight relationship between criterion level and index level.

\begin{tabular}{|c|c|c|c|c|}
\hline Criteria layer & Weight & Index layer & Weight & Target weight \\
\hline \multirow{4}{*}{$U_{1}$ (temperature condition) } & \multirow{4}{*}{0.29} & Temperature outside the tunnel & 0.1 & 0.029 \\
\hline & & Ground temperature of the surrounding rock & 0.4 & 0.116 \\
\hline & & Driving density & 0.3 & 0.087 \\
\hline & & Wind speed in the tunnel & 0.2 & 0.058 \\
\hline \multirow{4}{*}{$U_{2}$ (hydrological condition) } & \multirow{4}{*}{0.29} & Void area length of the surrounding rock between lining & 0.49 & 0.1421 \\
\hline & & Annual precipitation & 0.10 & 0.029 \\
\hline & & Blockage rate of the drain pipe & 0.25 & 0.0725 \\
\hline & & Waterproof design of three seams & 0.16 & 0.0464 \\
\hline \multirow{4}{*}{$U_{3}$ (surrounding rock condition) } & \multirow{4}{*}{0.13} & Buried depth & 0.08 & 0.0104 \\
\hline & & Fracture rate of the surrounding rock & 0.38 & 0.0494 \\
\hline & & Lining strength & 0.23 & 0.0299 \\
\hline & & Dissolution and invasion of the surrounding rock & 0.31 & 0.0403 \\
\hline \multirow{4}{*}{$U_{4}$ (engineering measure condition) } & \multirow{4}{*}{0.29} & Design issues & 0.23 & 0.0667 \\
\hline & & Construction issues & 0.53 & 0.1537 \\
\hline & & Operation and maintenance problems & 0.18 & 0.0522 \\
\hline & & Remedial measures & 0.06 & 0.0174 \\
\hline
\end{tabular}

TABLE 9: Value of influencing factors of frost damage in the portal section.

\begin{tabular}{lc}
\hline Influencing factors of frost damage & Measured value \\
\hline Temperature outside the tunnel $/{ }^{\circ} \mathrm{C}$ & -12.8 \\
Ground temperature of the surrounding rock $/{ }^{\circ} \mathrm{C}$ & 7.0 \\
Driving density/(pairs/h) & 3.0 \\
Wind speed in the tunnel/(m/s) & 1.8 \\
Void area length of the surrounding rock between lining/m & 4.2 \\
Annual precipitation $/ \mathrm{mm}$ & 392.8 \\
Blockage rate of the drain pipe & 0.1 \\
Waterproof design of three seams & 0.85 \\
Buried depth/m & 50 \\
Fracture rate of the surrounding rock & 1.5 \\
Lining strength & 0.8 \\
Dissolution and invasion of the surrounding rock & 0.3 \\
Design issues & 0.8 \\
Construction issues & 0.8 \\
Operation and maintenance problems & 0.9 \\
Remedial measures & 0.9 \\
\hline
\end{tabular}

$$
\begin{aligned}
& U_{1}=W_{U 1} \circ R_{1}=\left(\begin{array}{llll}
0.1 & 0.4 & 0.3 & 0.2
\end{array}\right) \circ\left[\begin{array}{cccc}
0.22 & 0.78 & 0 & 0 \\
0 & 0 & 0.4 & 0.6 \\
0.5 & 0.5 & 0 & 0 \\
0.2 & 0.8 & 0 & 0
\end{array}\right]=\left(\begin{array}{llll}
0.212 & 0.388 & 0.16 & 0.24
\end{array}\right) \\
& U_{2}=W_{U 2} \circ R_{2}=\left(\begin{array}{llll}
0.49 & 0.1 & 0.25 & 0.16
\end{array}\right) \circ\left[\begin{array}{cccc}
0.4 & 0.6 & 0 & 0 \\
0.518 & 0.482 & 0 & 0 \\
1 & 0 & 0 & 0 \\
1 & 0 & 0 & 0
\end{array}\right]=\left(\begin{array}{llll}
0.6578 & 0.3422 & 0 & 0
\end{array}\right), \\
& U_{3}=W_{U 3} \circ R_{3}=\left(\begin{array}{llll}
0.08 & 0.38 & 0.23 & 0.31
\end{array}\right) \circ\left[\begin{array}{cccc}
0 & 0 & 0 & 1 \\
0 & 0.9 & 0.1 & 0 \\
0.5 & 0.5 & 0 & 0 \\
0 & 0 & 0 & 1
\end{array}\right]=\left(\begin{array}{llll}
0.115 & 0.457 & 0.038 & 0.39
\end{array}\right)
\end{aligned}
$$




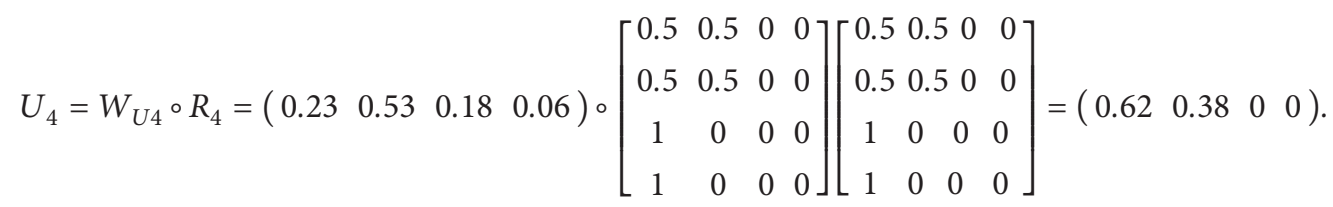

4.4. Operation of the Second-Level Intelligent Fuzzy Comprehensive Evaluation Model. The second level of fuzzy synthesis is as follows:

$$
V=W_{U} \circ R=\left(\begin{array}{llll}
0.29 & 0.29 & 0.13 & 0.29
\end{array}\right) \circ\left[\begin{array}{cccc}
0.212 & 0.388 & 0.16 & 0.24 \\
0.6578 & 0.3422 & 0 & 0 \\
0.115 & 0.457 & 0.038 & 0.39 \\
0.62 & 0.38 & 0 & 0
\end{array}\right]=\left(\begin{array}{llll}
0.446992 & 0.381368 & 0.05134 & 0.1203
\end{array}\right)
$$

The maximum membership principle is used to evaluate the calculation results, that is, which value of $V$ is the largest and the frost damage of the tunnel is in which level. It can be seen that the frost damage degree of the tunnel portal section is class I (no frost damage or slight frost damage). It is recommended to set the thermal insulation layer and adopt general ditch in the portal section. The thermal insulation ditch is set up within $500 \mathrm{~m}$ of the tunnel portal. Since 2014, only slight freezing phenomenon has been seen at the tunnel portal section, and no obvious frost damage has occurred. The tunnel is in good operation condition, which is consistent with the results of analysis of the intelligent evaluation model proposed in this paper.

\section{Conclusion}

(1) Based on the investigation results of 122 seasonal frozen soil tunnels in high-latitude areas of China, four key influencing factors are determined, and an intelligent evaluation system of tunnel frost damage in cold areas is proposed. Taking a tunnel in cold regions as an application example, the scientificity and rationality of the intelligent evaluation system are proved.

(2) The intelligent fuzzy comprehensive evaluation method can be used to describe the relationship among influencing factors of tunnel frost damage in cold regions, the weight of influencing factors is calculated by analytic hierarchy process, and the main risk sources of tunnel frost damage are found out, which is an efficient and practical method for pre-evaluation.

(3) By using the subordinate function method, the improvement from qualitative analysis to quantitative index calculation is realized. The blindness of engineering analogy construction is avoided, and the scientificity and accuracy of renovation measures for frost damage have been improved. At the same time, the research results provide a theoretical basis for the improvement of the intelligent evaluation system of tunnel frost damage in cold regions.

\section{Data Availability}

The data used to support the findings of this study are included within the article.

\section{Conflicts of Interest}

The authors declare that there are no conflicts of interest regarding the publication of this paper.

\section{Acknowledgments}

The authors appreciate the support from the National Natural Science Foundation of China (no. 51778380).

\section{References}

[1] G. Barla, M. Bonini, and M. Semeraro, "Analysis of the behaviour of a yield-control support system in squeezing rock," Tunnelling and Underground Space Technology Incorporating Trenchless Technology Research, vol. 26, no. 1, pp. 146-154, 2010.

[2] W. Yu, W. Wang, X. Chen, and S. Du, "Field investigations of high stress soft surrounding rocks and deformation control," Journal of Rock Mechanics and Geotechnical Engineering, vol. 7, no. 4, pp. 421-433, 2015.

[3] Y. S. Shen, Z. Z. Wang, J. Yu, X. Zhang, and B. Gao, "Shaking table test on flexible joints of mountain tunnels passing through normal fault," Tunnelling and Underground Space Technology, vol. 98, Article ID 103299, 2020.

[4] D.-Y. Wang, J.-S. Qi, G.-Y. Cui, Y. Yang, and J. Chang, "Model test on bearing characteristics of basalt fiber-reinforced concrete lining," Advances in Materials Science and Engineering, vol. 2020, no. 03, pp. 1-10, Article ID 3891343, 2020.

[5] N. Buratti, C. Mazzotti, and M. Savoia, "Post-cracking behaviour of steel and macro-synthetic fibre-reinforced 
concretes," Construction and Building Materials, vol. 25, no. 5, pp. 2713-2722, 2010.

[6] Z. Wang, X.-L. Zhao, G. Xian, G. Wu, R. K. Singh Raman, and S. Al-Saadi, "Durability study on interlaminar shear behaviour of basalt-, glass- and carbon-fibre reinforced polymer (B/ G/CFRP) bars in seawater sea sand concrete environment," Construction and Building Materials, vol. 156, pp. 985-1004, 2017.

[7] T. M. Borhan, "Properties of glass concrete reinforced with short basalt fibre," Materials and Design, vol. 42, pp. 265-271, 2012.

[8] T. Kasper, C. Edvardsen, G. Wittneben et al., "Lining design for the district heating tunnel in Copenhagen with steel fibre reinforced concrete segments," Tunnelling and Underground Space Technology Incorporating Trenchless Technology Research, vol. 23, no. 5, pp. 574-587, 2007.

[9] Z. Z. Wang, L. Jiang, and Y. Gao, "Shaking table test of seismic response of immersed tunnels under effect of water," Soil Dynamics and Earthquake Engineering, vol. 116, pp. 436-445, 2019.

[10] Z. Z. Wang, Y. J. Jiang, and C. A. Zhu, "Seismic energy response and damage evolution of tunnel lining structures," European Journal of Environmental and Civil Engineering, vol. 23, no. 6, pp. 758-770, 2019.

[11] J. Branston, S. Das, S. Y. Kenno, C. Taylor, and C. Taylor, "Mechanical behaviour of basalt fibre reinforced concrete," Construction and Building Materials, vol. 124, pp. 878-886, 2016.

[12] Y. V. Lipatov, S. I. Gutnikov, M. S. Manylov, E. S. Zhukovskaya, and B. I. Lazoryak, "High alkali-resistant basalt fiber for reinforcing concrete," Materials \& Design, vol. 73, pp. 60-66, 2015.

[13] C. High, H. M. Seliem, A. El-Safty, S. H. Rizkalla, and Rizkalla, "Use of basalt fibers for concrete structures," Construction and Building Materials, vol. 96, pp. 37-46, 2015.

[14] G. Campione, L. La Mendola, A. Monaco, A. Valenza, and V. Fiore, "Behavior in compression of concrete cylinders externally wrapped with basalt fibers," Composites Part B: Engineering, vol. 69, pp. 576-586, 2015.

[15] V. Brik, V. Ramakrishnan, and N. Tolmare, Performance Evaluation of 3-D Basalt Fibre Reinforced Concrete \&Basalt Rod Reinforced Concrete. IDEA Program Final Report, Transportation Research Board, Washington, DC, USA, 1998.

[16] H. Wang, L. Yuan, and H. Song, "Experimental study on mechanical property of chopped basalt fiber reinforced concrete," Building Structure, vol. 43, no. s2, pp. 562-564, 2013.

[17] J. Lian, Y. Yang, M. Yang et al., "Experimental research on the mechanical behavior of chopped basalt fiber reinforced concrete," Industrial Construction, vol. 37, no. 6, pp. 8-10, 2007.

[18] J. Sim, C. Park, and D. Y. Moon, "Characteristics of basalt fiber as a strengthening material for concrete structures," Composites Part B: Engineering, vol. 36, no. 6-7, pp. 504-512, 2005.

[19] M. Peng, H. Huang, Q.-he Liao et al., "Test study on basic mechanical properties of basalt fiber reinforced concrete," Concrete, vol. 33, no. 1, pp. 74-75, 2012.

[20] T. Ayub, N. Shafiq, and M. F. Nuruddin, "Mechanical properties of high-performance concrete reinforced with basalt fibers," Procedia Engineering, vol. 77, pp. 131-139, 2014.

[21] C. Jiang, K. Fan, F. Wu, and D. Chen, "Experimental study on the mechanical properties and microstructure of chopped basalt fibre reinforced concrete," Materials \& Design, vol. 58, pp. 187-193, 2014. 